\title{
Direct oral anticoagulants in the treatment of venous thromboembolism, with a focus on patients with pulmonary embolism: an evidence-based review
}

\author{
This article was published in the following Dove Press journal: \\ Vascular Health and Risk Management \\ 7 November 2014 \\ Number of times this article has been viewed
}

\author{
Antonio Gómez-Outes' \\ $M^{a}$ Luisa Suárez-Gea' \\ Ramón Lecumberri ${ }^{2}$ \\ Ana Isabel Terleira- \\ Fernández ${ }^{3,4}$ \\ Emilio Vargas-Castrillón ${ }^{3,4}$ \\ 'Division of Pharmacology and Clinical \\ Evaluation, Medicines for Human Use, \\ Spanish Agency for Medicines and \\ Medical Devices (AEMPS), Madrid, \\ Spain; ${ }^{2}$ Department of Hematology, \\ University Clinic of Navarra, \\ Pamplona, Spain; ${ }^{3}$ Department of \\ Clinical Pharmacology, Hospital \\ Clínico, Madrid, Spain; ${ }^{4}$ Department \\ of Pharmacology, Universidad \\ Complutense, Madrid, Spain
}

Abstract: Pulmonary embolism (PE) is a relatively common cardiovascular emergency. PE and deep vein thrombosis (DVT) are considered expressions of the same disease, termed as venous thromboembolism (VTE). In the present review, we describe and meta-analyze the efficacy and safety data available with the direct oral anticoagulants (DOAC; dabigatran, rivaroxaban, apixaban, edoxaban) in clinical trials testing these new compounds in the acute/ long-term and extended therapy of VTE, providing subgroup analyses in patients with index PE. We analyzed ten studies in 35,019 randomized patients. A total of 14,364 patients $(41 \%)$ had index PE. In the acute/long-term treatment of VTE, the DOAC showed comparable efficacy in preventing recurrent VTE to standard treatment in patients with index PE (risk ratio [RR]: 0.88; 95\% confidence interval [CI]: 0.70-1.11) and index DVT (RR: 0.93; 95\% CI: $0.75-1.16$ ) ( $P$ for subgroup differences $=0.76$ ). VTE recurrence depending on PE anatomical extension and presence/absence of right ventricular dysfunction was only reported in two trials, with results being consistent with those obtained in the overall study populations. In the single trial comparing extended therapy of VTE with DOAC versus warfarin, the point estimate for recurrent VTE tended to disfavor the DOAC in patients with index PE (RR: $2.05 ; 95 \% \mathrm{CI}$ : 0.83-5.03) and in patients with index DVT (RR: 1.11 ; 95\% CI: $0.49-2.50)$ ( $P$ for subgroup differences $=0.32$ ). In trials that compared DOAC versus placebo for extended therapy, the reduction in recurrent VTE was consistent in patients with PE (RR: 0.15; 95\% CI: 0.01-1.82) and in patients with DVT (RR: $0.25 ; 95 \% \mathrm{CI}$ : 0.10-0.61) ( $P$ for subgroup differences $=0.71$ ). The DOAC were associated with a consistently lower risk of clinically relevant bleeding (CRB) than standard treatment of acute VTE and higher risk of CRB than placebo for extended therapy of VTE regardless of index event. In summary, the DOAC were as effective as, and safer than, standard treatment of (hemodynamically stable) PE. Their efficacy in preventing recurrent VTE seemed consistent regardless of anatomical extension of PE (extensive, intermediate, or limit) or presence/absence of right ventricular dysfunction although the data are limited. For extended therapy, the DOAC were more effective than placebo in preventing recurrent VTE but were associated with an increase in CRB regardless of index event.

Keywords: anticoagulant, pulmonary embolism, dabigatran, apixaban, rivaroxaban, edoxaban

\section{Introduction}

Pulmonary embolism (PE) is a relatively common cardiovascular emergency. PE occurs when clots break off from deep vein walls (deep vein thrombosis [DVT]), usually from the lower limbs, and travel through the right side of the heart to the pulmonary 
arteries occluding the pulmonary arterial bed. The broader term venous thromboembolism (VTE) refers to DVT, PE, or a combination of both, and has a reported annual incidence of 1-2 cases per 1,000 inhabitants in Western countries. ${ }^{1} \mathrm{PE}$ and DVT are considered as expressions of the same disease, as in different studies, about $70 \%$ of patients with documented symptomatic PE had DVT, ${ }^{2}$ and patients presenting with documented DVT have been shown to have silent PE or perfusion defects on ventilation/perfusion lung scan in $30 \%-70 \%$ of cases. ${ }^{3,4}$

PE can be broadly classified as either high-risk PE (hemodynamically unstable: presence of shock or hypotension, defined as a systolic blood pressure $<90 \mathrm{mmHg}$ or a pressure drop of $\geq 40 \mathrm{mmHg}$ for 15 minutes if not caused by new-onset arrhythmia, hypovolemia, or sepsis; early mortality risk $>15 \%$ ) or non-high-risk PE (hemodynamically stable; early mortality risk $<15 \%) .{ }^{5}$ Non-high-risk PE can be further stratified according to the presence of markers of right ventricular dysfunction (RVD) and/or myocardial injury into intermediate- and low-risk PE. Intermediate-risk PE (early mortality risk $\approx 3 \%-15 \%$ ) is diagnosed if at least one of the RVD markers: 1) right ventricular (RV) dilatation, hypokinesis, or pressure overload on echocardiography; 2) RV dilatation on spiral computed tomography; 3) brain natriuretic peptide (BNP) or N-terminal (NT)-pro-BNP elevation; 4) elevated right heart pressure at right heart catheterization; or one myocardial injury marker, cardiac troponin T or I, is positive. ${ }^{5}$ Low-risk PE is diagnosed when all checked RVD and myocardial injury markers are found negative (early mortality risk $<1 \%$ ). Some clinical scores, such as the simplified PE severity index, may also be useful to identify low-risk PE patients who are potential candidates for outpatient treatment. ${ }^{6}$ Patients presenting with hemodynamic instability (high-risk PE) are usually treated with either thrombolytic therapy or pulmonary embolectomy followed by anticoagulant therapy, while most hemodynamically stable patients (non-high risk PE) can be treated with anticoagulation alone.

The basic anticoagulant treatment strategy is similar for patients with PE or DVT, and generally includes a parenteral anticoagulant (eg, low-molecular-weight heparin (LMWH), unfractionated heparin, or fondaparinux) for at least 5 days and until the international normalized ratio (INR) is 2.0 or above for at least 24 hours (initial therapy), overlapping with and followed by an oral vitamin $\mathrm{K}$ antagonist (VKA) (dose adjusted to keep an INR between 2.0 and 3.0) for at least 3 months (long-term therapy). ${ }^{7}$ At this point, the decision to continue with anticoagulant treatment depends on the balance between the risk of VTE recurrences if anticoagulation is withdrawn and the risk of bleeding if it is continued. Patients with ongoing risk factors and patients with unprovoked VTE are often prescribed extended therapy, provided that the bleeding risk is not excessive. ${ }^{7}$

Despite LMWH or fondaparinux being effective and safe, they still require daily parenteral subcutaneous administration. In addition, they are mainly cleared through the kidneys, and their use in patients with severe renal insufficiency may be problematic. On the other hand, the narrow therapeutic window and variability in response of VKA implies that frequent anticoagulant monitoring (using the prothrombin time and its reporting as the INR) is necessary to avoid a subtherapeutic anticoagulation associated with an increased risk of thrombosis or an excessive anticoagulation that increases the risk of bleeding. Such monitoring is inconvenient for patients and medical staff, and costly for health care payers.

In recent years, several direct oral anticoagulants (DOAC) have been developed for the treatment of VTE, among other indications. ${ }^{8}$ DOAC directly inhibit either thrombin or activated factor $\mathrm{X}$ (FXa). ${ }^{9}$ Among them, the oral direct thrombin inhibitor dabigatran etexilate (Pradaxa ${ }^{\circledR}$, Boehringer Ingelheim, Ingelheim, Germany $)^{10}$ and the oral direct FXa inhibitors rivaroxaban (Xarelto ${ }^{\circledR}$, Bayer AG, Leverkusen, Germany $)^{11}$ and apixaban (Eliquis ${ }^{\circledR}$, Bristol-Myers Squibb, New York, NY, USA) ${ }^{12}$ are currently approved in the European Union, North America, and other regions in several indications related to anticoagulation, including the treatment of VTE, while the oral direct FXa inhibitor edoxaban (Lixiana ${ }^{\circledR}$, Daiichi-Sankyo, Tokyo, Japan $)^{13}$ is approved in Japan for thromboprophylaxis after major orthopedic surgery and is currently under regulatory review in the European Union and other regions for the treatment of VTE and for the prevention of stroke and systemic embolism in patients with atrial fibrillation. Their pharmacology is well characterized (Table 1). ${ }^{14-30}$ They are given orally in fixed doses once or twice daily, and they lack validated and available antidotes. ${ }^{10-13}$

In this review, we describe and meta-analyze the efficacy and safety data available with the DOAC in clinical trials testing these new compounds in VTE, with a focus on patients with index PE, and we discuss their potential advantages and drawbacks over existing therapies in patients with VTE.

\section{Methods \\ Bibliographic search}

A search in Medline database (up to 1 June 2014) and clinical trial registries (ie, clinicaltrials.gov) was conducted using the 


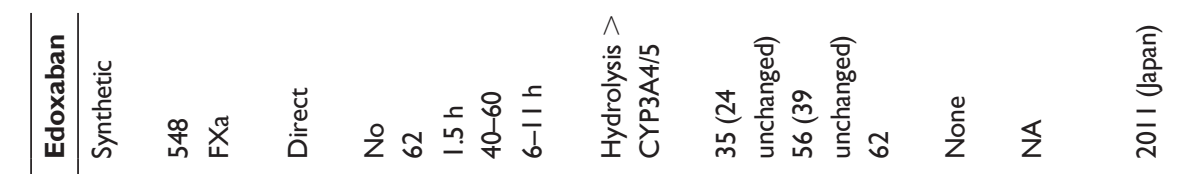

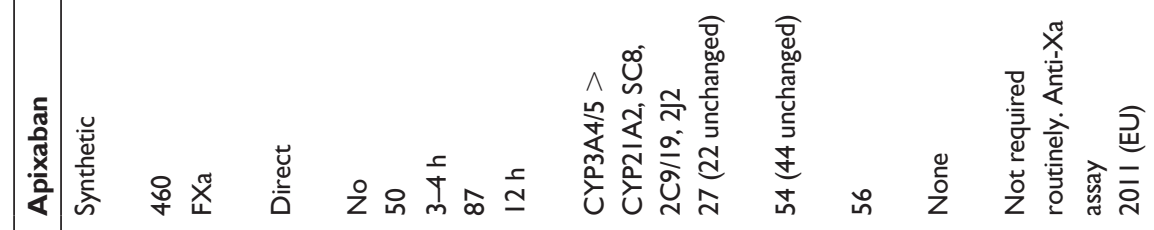

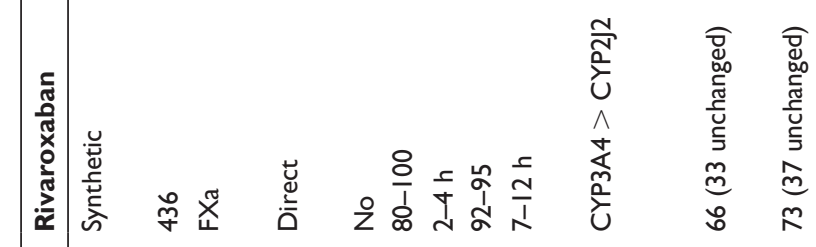

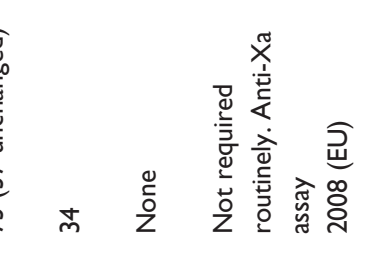

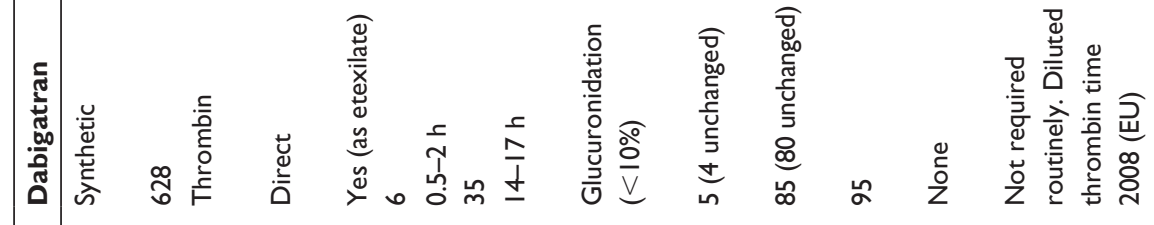

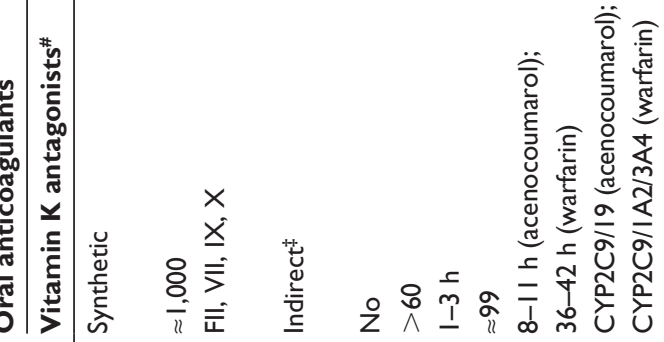

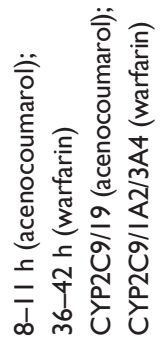<smiles>CCC</smiles>

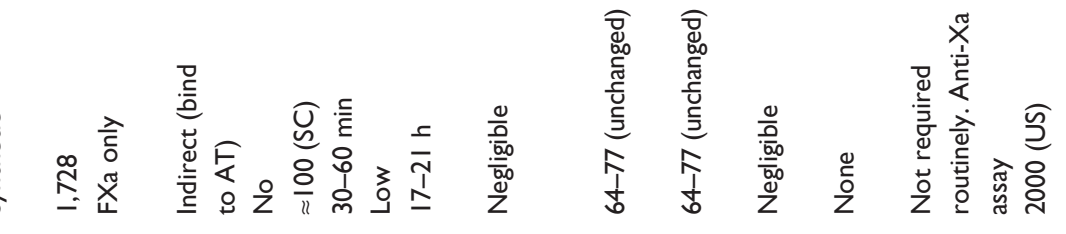

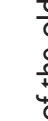

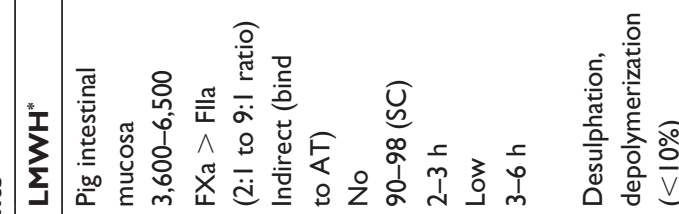<smiles>[AlH2]</smiles> 
terms: "dabigatran", "rivaroxaban", "apixaban", "edoxaban", and "pulmonary embolism". We also searched regulatory agencies' websites (European Medicines Agency, US Food and Drug Administration) and relevant conference proceedings related to anticoagulant therapy.

\section{Study selection criteria}

We included randomized controlled trials comparing a DOAC (dabigatran, rivaroxaban, apixaban, and edoxaban) with the standard treatment for acute VTE or with warfarin or placebo for extended treatment of VTE.

\section{Data extraction and quality assessment}

We collected outcome data on the overall trial populations as well as by index event at baseline: index PE (with or without concomitant DVT) or index DVT (without PE). Primary efficacy outcome was recurrent symptomatic VTE (ie, the composite of recurrent DVT, recurrent non-fatal PE, and VTE-related death) and primary safety outcome was clinically relevant bleeding (CRB) (ie, the composite of major and clinically relevant non-major bleeding). We also extracted data on clinical trials design (eg, superiority, non-inferiority, duration of treatment and follow-up, inclusion and exclusion criteria, and outcomes definitions), treatment characteristics (eg, dosage used in the experimental and control groups), and patients' characteristics (age and sex; percentage of patients evaluable for efficacy and safety). Study quality was assessed using the Cochrane Collaboration's tool for assessing risk of bias in randomized studies. ${ }^{31}$

\section{Data synthesis and analysis}

We carried out direct comparisons between the DOAC and standard treatment (initial/long-term therapy), placebo or warfarin (extended therapy) on an intention-to-treat basis. ${ }^{32}$ We included the randomized population in the overall analysis. Clinical outcomes were analyzed in subgroups of patients with index PE versus those with index DVT when disaggregated data were available. Subgroup analyses by index event (PE or DVT) were conducted in the assessable population for efficacy and safety, as reported in the original publications. A random effects meta-analysis was carried out by conventional methods, as described by DerSimonian and Laird. ${ }^{33}$ Heterogeneity was assessed using the Cochran $Q$ test $^{34}$ and the Higgins $I^{2}$ test. ${ }^{35}$ A Cochran's $Q P<0.05$ and $I^{2}>50 \%$ were considered to show significant heterogeneity. Calculations were performed using RevMan software, version 5.2 (The Nordic Cochrane Centre, Copenhagen,
Denmark) and StatsDirect software, version 2.8.0 (StatsDirect Ltd, Cheshire, UK).

\section{Results}

\section{Characteristics of studies and patients}

Table 2 shows the characteristics of the studies and patients. We included ten studies in 35,019 randomized patients. A total of 14,364 patients $(41.0 \%)$ had index PE.

The six studies in the initial/long-term therapy of VTE ${ }^{36-41}$ included 27,127 randomized patients (Table 2). Of them, 11,613 patients $(42 \%)$ had index PE. The four studies in the extended therapy of VTE ${ }^{38,42,43}$ comprised 7,892 randomized patients (Table 2). Of them, 2,751 patients (35\%) had index PE. Mean age of patients was 55-58 years across trials and 55\%-61\% were males (Table 2). Ethnic group distribution was reported in seven trials. ${ }^{36-39,42}$ Across studies, the majority of patients included were Caucasians (70\%-95\%), followed by Asians (2\%-21\%) and Blacks or African Americans ( $1 \%-4 \%$ ). Extensive PE was present in $24 \%-46 \%$ of patients with index PE (data only available from Oral Direct Factor Xa Inhibitor Rivaroxaban in Patients With Acute Symptomatic Pulmonary Embolism [EINSTEIN PE], Efficacy and Safety Study of Apixaban for the Treatment of Deep Vein Thrombosis or Pulmonary Embolism [AMPLIFY] and Comparative Investigation of Low Molecular Weight [LMW] Heparin/ Edoxaban Tosylate [DU176b] Versus [LMW] Heparin/Warfarin in the Treatment of Symptomatic Deep-Vein Blood Clots and/or Lung Blood Clots [HOKUSAI-VTE]) (Table 2).

In the initial/long-term therapy of VTE, a single drug approach was used in rivaroxaban and apixaban trials, while heparin lead-in was used in dabigatran and edoxaban trials. Treatment durations ranged between 3 months and 12 months in clinical trials in the acute/long-term therapy of VTE and between 6 months and 18 months in the extended therapy of VTE (Table 2). All studies in the acute/long-term therapy of VTE and Secondary Prevention of Venous Thrombo Embolism (VTE) (RE-MEDY) ${ }^{42}$ study in extended therapy of VTE used a non-inferiority approach, while placebo-controlled studies in extended therapy of VTE were superiority trials (Table 2). In placebo-controlled trials, patients were recruited if there was clinical equipoise about the continuation or cessation of anticoagulant therapy. All studies but two (Oral Direct Factor Xa Inhibitor Rivaroxaban in Patients With Acute Symptomatic Deep Vein Thrombosis [EINSTEIN DVT] and PE) were double blinded (Table 2). Methods for assessment of recurrent VTE were consistent across studies. ${ }^{36-43}$ DVT diagnosis was established by compression ultrasonography or venography of leg veins, while non-fatal PE was diagnosed 


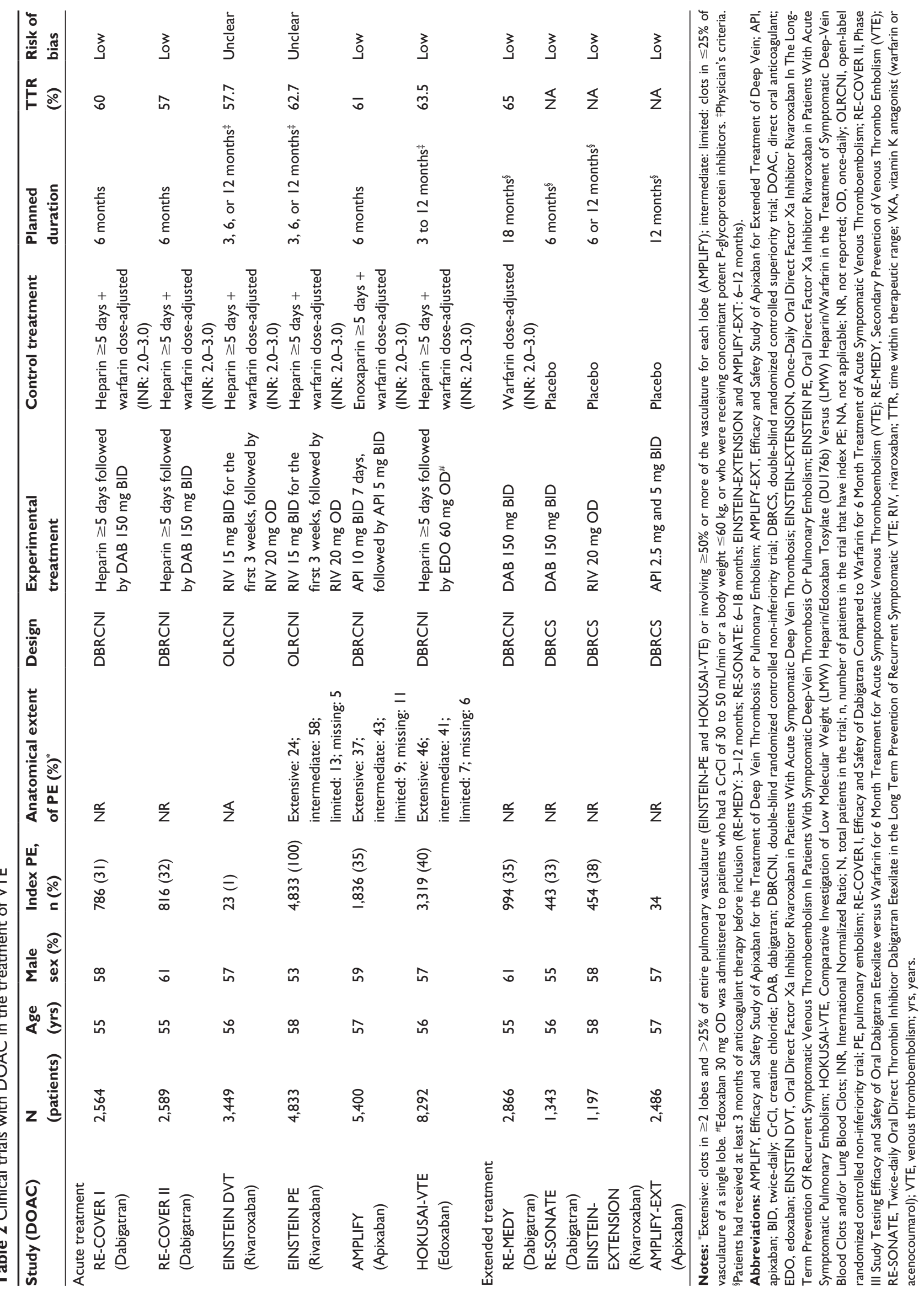


by ventilation-perfusion lung scanning, angiography, or spiral computed tomography of pulmonary arteries. Diagnosis of fatal PE was based on objective testing, autopsy, or death that could not be attributed to a documented cause and for which PE could not be ruled out. CRB definition was based on that used by the van Gogh trialists ${ }^{44}$ in studies with rivaroxaban, apixaban, and edoxaban, but all dabigatran studies used a different definition. ${ }^{36}$ Time in therapeutic range (TTR) ranged between $57 \%$ and $65 \%$ across studies that included warfarin as control treatment (Table 2). ${ }^{36-42}$

Risk of bias was assessed as "low" in the eight doubleblinded studies and "uncertain" in the two open-label studies, EINSTEIN DVT and PE (Table 2).

\section{Recurrent VTE}

\section{Initial and long-term treatment of VTE}

In the overall populations, the DOAC were as effective as standard therapy (risk ratio [RR]: 0.91; 95\% confidence interval [CI]: 0.79-1.06), with no evidence of heterogeneity (Figure 1). A total of 11,589 patients (DOAC: 5,794; standard therapy: 5,795) with index $\mathrm{PE}$ and 15,434 patients (DOAC: 7,718; standard therapy: 7,716) with index DVT were assessable for recurrent VTE (Figure 2A). The DOAC showed comparable efficacy in preventing recurrent VTE to standard treatment in patients with index PE (RR: 0.88; 95\% CI: 0.70-1.11) and index DVT (RR: 0.93; 95\% CI: 0.75-1.16) ( $P$ for subgroup differences $=0.76$ ) (Figure 2A).

VTE recurrence depending on PE anatomical extension and presence/absence of RVD was only reported in two trials. $^{39,41}$ In EINSTEIN PE, the rates of recurrent VTE in the rivaroxaban versus standard-therapy group were $1.7 \%$ (10 of 597) versus $1.4 \%$ ( 8 of 576) among patients with anatomically extensive PE at baseline, respectively; $2.5 \%$ (35 of 1,392 ) versus $2.2 \%$ (31 of 1424) in intermediate PE, respectively; and $1.6 \%$ (5 of 309 patients) versus $1.3 \%$ (4 of $299)$ in limited PE at baseline, respectively. ${ }^{39}$ In HOKUSAIVTE, $28 \%(n=938)$ of patients with PE $(n=3,319)$ had RVD (NT-pro-BNP level $\geq 500 \mathrm{pg} / \mathrm{mL}$ ). The rate of recurrent VTE in this subgroup was 3.3\% in the edoxaban group and $6.2 \%$ in the warfarin group (HR: 0.52; 95\% CI: 0.28-0.98). ${ }^{41}$ Similar results were observed among patients with RVD assessed by the presence of RV dilatation on computed tomography (HR: 0.42 ; 95\% CI: $0.15-1.20){ }^{41}$

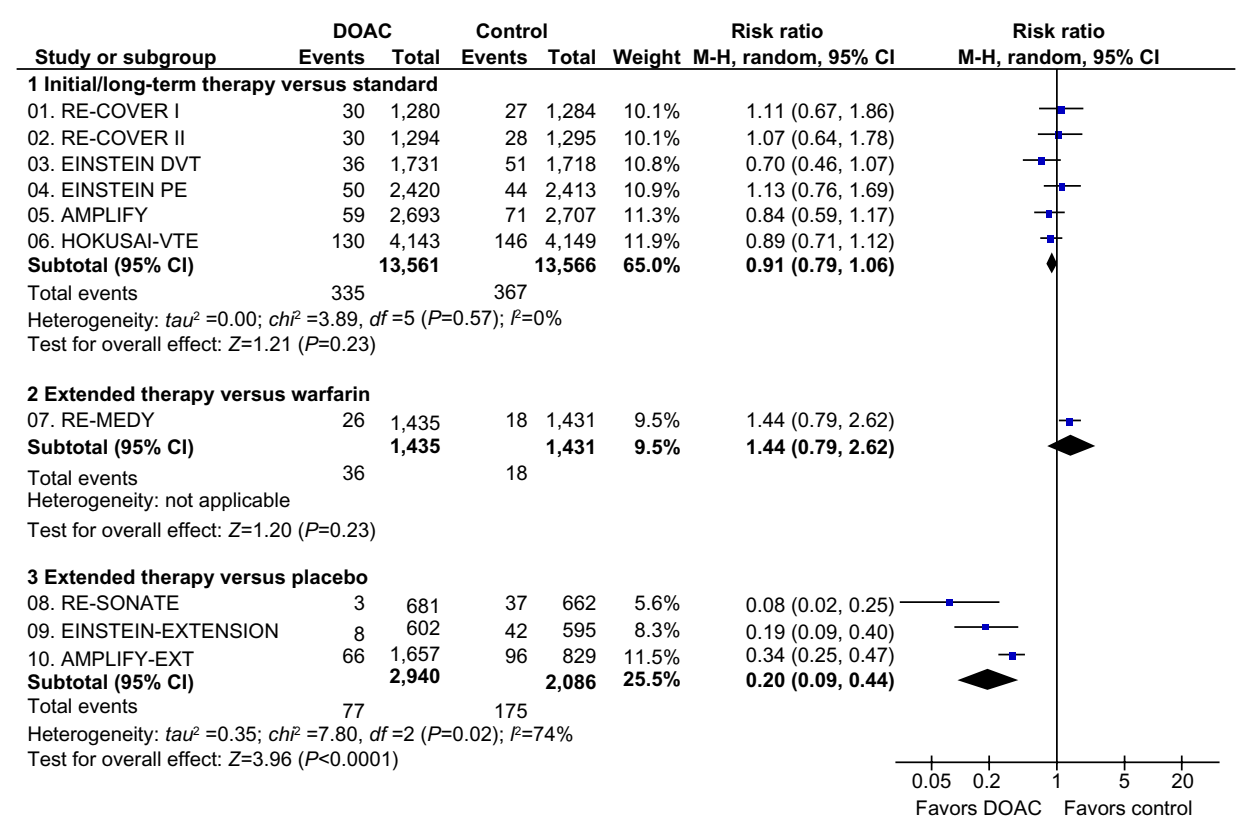

Figure I Recurrent VTE in clinical trials with DOAC in the treatment of VTE.

Abbreviations: AMPLIFY, Efficacy and Safety Study of Apixaban for the Treatment of Deep Vein Thrombosis or Pulmonary Embolism; AMPLIFY-EXT, Efficacy and Safety Study of Apixaban for Extended Treatment of Deep Vein; Cl, confidence interval; df, degrees of freedom; DOAC, direct oral anticoagulant; DVT, deep vein thrombosis; EINSTEIN DVT, Oral Direct Factor Xa Inhibitor Rivaroxaban in Patients With Acute Symptomatic Deep Vein Thrombosis; EINSTEIN-EXTENSION, Once-Daily Oral Direct Factor Xa Inhibitor Rivaroxaban In The Long-Term Prevention Of Recurrent Symptomatic Venous Thromboembolism In Patients With Symptomatic Deep-Vein Thrombosis Or Pulmonary Embolism; EINSTEIN PE, Oral Direct Factor Xa Inhibitor Rivaroxaban in Patients With Acute Symptomatic Pulmonary Embolism; HOKUSAIVTE, Comparative Investigation of Low Molecular Weight (LMW) Heparin/Edoxaban Tosylate (DUI76b) Versus (LMW) Heparin/Warfarin in the Treatment of Symptomatic Deep-Vein Blood Clots and/or Lung Blood Clots; M-H, Mantel-Haenszel; PE, pulmonary embolism; RE-COVER I, Efficacy and Safety of Dabigatran Compared to Warfarin for 6 Month Treatment of Acute Symptomatic Venous Thromboembolism; RE-COVER II, Phase III Study Testing Efficacy and Safety of Oral Dabigatran Etexilate versus Warfarin for 6 Month Treatment for Acute Symptomatic Venous Thromboembolism (VTE); RE-MEDY, Secondary Prevention of Venous Thrombo Embolism (VTE); RE-SONATE, Twice-daily Oral Direct Thrombin Inhibitor Dabigatran Etexilate in the Long Term Prevention of Recurrent Symptomatic VTE; VTE, venous thromboembolism. 


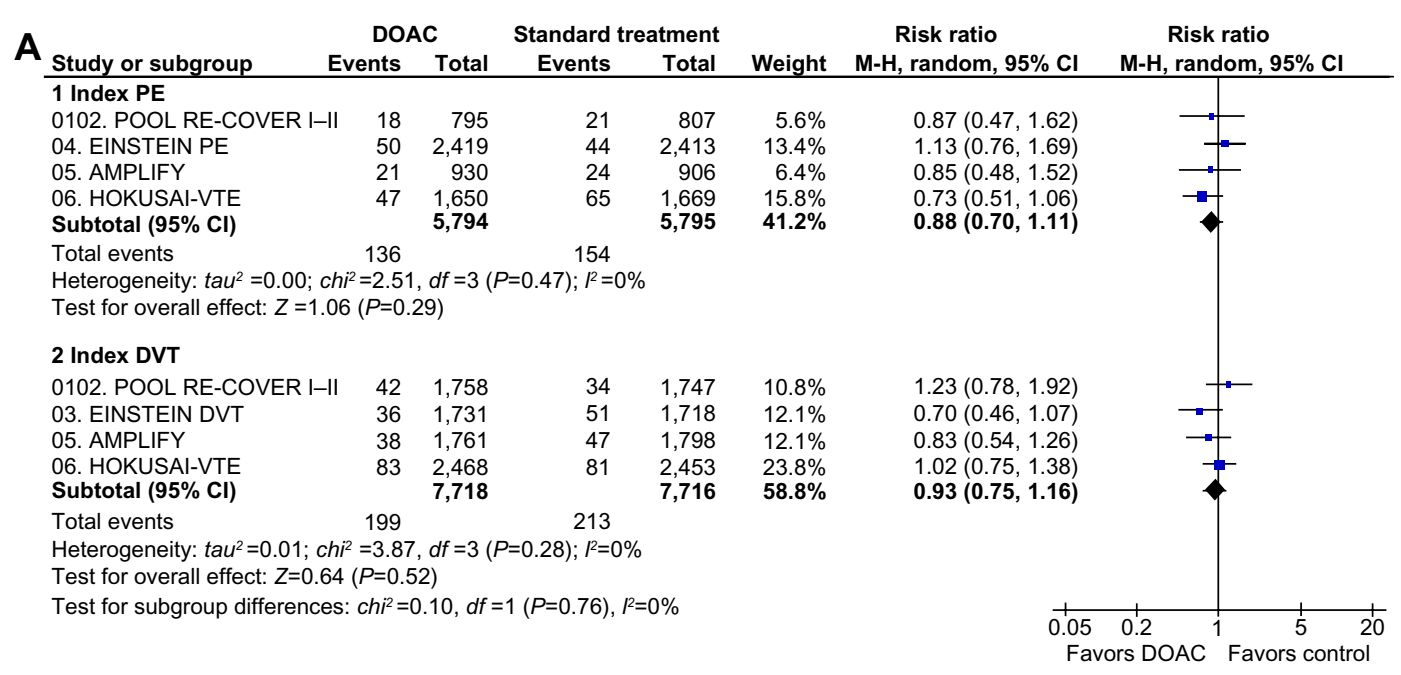

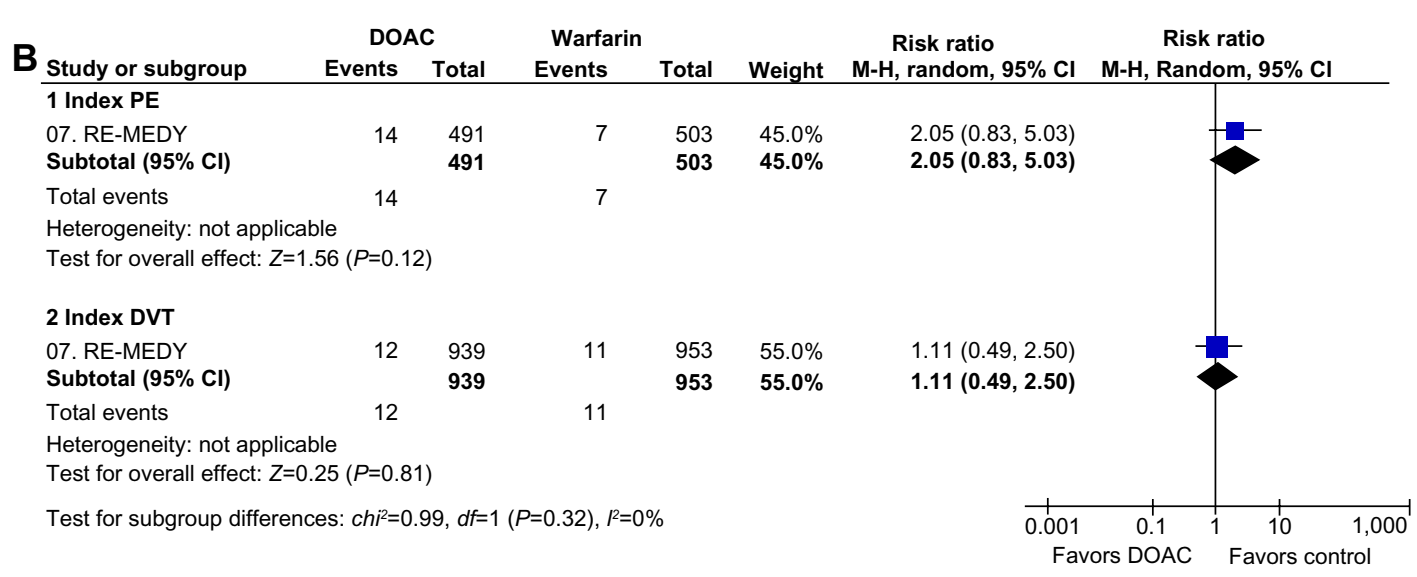

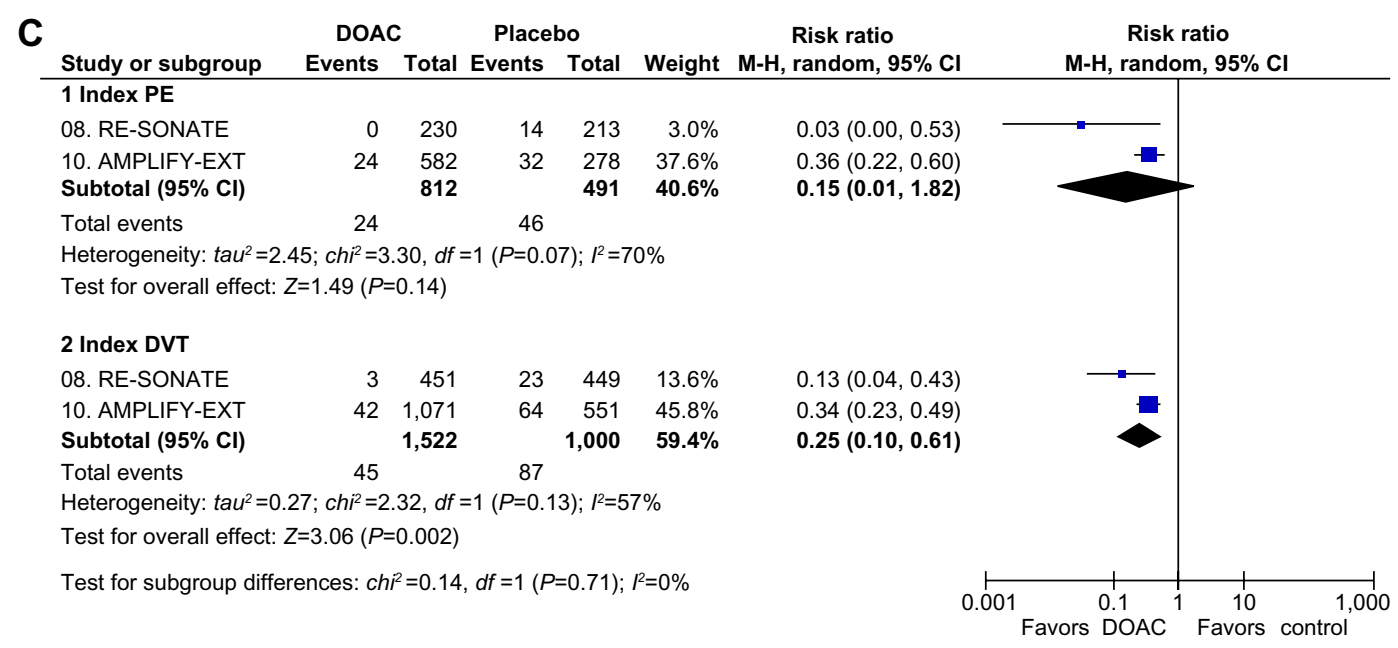

Figure 2 Subgroup analysis of recurrent VTE depending on index event (PE or DVT) in clinical trials with DOAC in the treatment of VTE.

Notes: (A) Initial/long-term therapy versus standard treatment. (B) Extended therapy versus warfarin. (C) Extended therapy versus placebo.

Abbreviations: AMPLIFY, Efficacy and Safety Study of Apixaban for the Treatment of Deep Vein Thrombosis or Pulmonary Embolism; AMPLIFY-EXT, Efficacy and Safety Study of Apixaban for Extended Treatment of Deep Vein; $\mathrm{Cl}$, confidence interval; $\mathrm{df}$, degrees of freedom; DOAC, direct oral anticoagulant; DVT, deep vein thrombosis; EINSTEIN DVT, Oral Direct Factor Xa Inhibitor Rivaroxaban in Patients With Acute Symptomatic Deep Vein Thrombosis; EINSTEIN-EXTENSION, Once-Daily Oral Direct Factor Xa Inhibitor Rivaroxaban In The Long-Term Prevention Of Recurrent Symptomatic Venous Thromboembolism In Patients With Symptomatic Deep-Vein Thrombosis Or Pulmonary Embolism; EINSTEIN PE, Oral Direct Factor Xa Inhibitor Rivaroxaban in Patients With Acute Symptomatic Pulmonary Embolism; HOKUSAIVTE, Comparative Investigation of Low Molecular Weight (LMW) Heparin/Edoxaban Tosylate (DUI76b) Versus (LMW) Heparin/Warfarin in the Treatment of Symptomatic Deep-Vein Blood Clots and/or Lung Blood Clots; M-H, Mantel-Haenszel; PE, pulmonary embolism; RE-COVER I, Efficacy and Safety of Dabigatran Compared to Warfarin for 6 Month Treatment of Acute Symptomatic Venous Thromboembolism; RE-COVER II, Phase III Study Testing Efficacy and Safety of Oral Dabigatran Etexilate versus Warfarin for 6 Month Treatment for Acute Symptomatic Venous Thromboembolism (VTE); RE-MEDY, Secondary Prevention of Venous Thrombo Embolism (VTE); RE-SONATE, Twice-daily Oral Direct Thrombin Inhibitor Dabigatran Etexilate in the Long Term Prevention of Recurrent Symptomatic VTE; VTE, venous thromboembolism. 


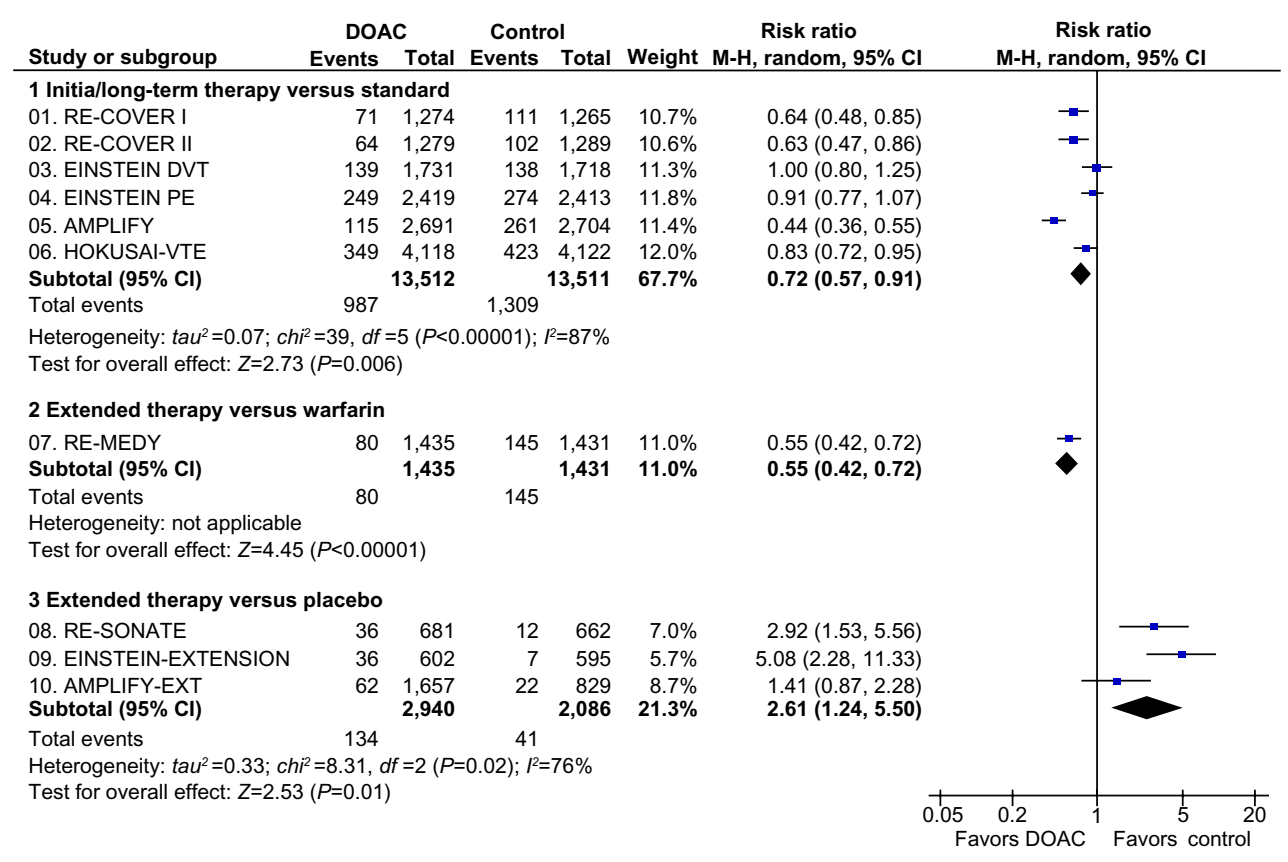

Figure 3 Major and clinically relevant nonmajor bleeding in clinical trials with DOAC in the treatment of VTE.

Abbreviations: AMPLIFY, Efficacy and Safety Study of Apixaban for the Treatment of Deep Vein Thrombosis or Pulmonary Embolism; AMPLIFY-EXT, Efficacy and Safety Study of Apixaban for Extended Treatment of Deep Vein; Cl, confidence interval; df, degrees of freedom; DOAC, direct oral anticoagulant; DVT, deep vein thrombosis; EINSTEIN DVT, Oral Direct Factor Xa Inhibitor Rivaroxaban in Patients With Acute Symptomatic Deep Vein Thrombosis; EINSTEIN-EXTENSION, Once-Daily Oral Direct Factor Xa Inhibitor Rivaroxaban In The Long-Term Prevention Of Recurrent Symptomatic Venous Thromboembolism In Patients With Symptomatic Deep-Vein Thrombosis Or Pulmonary Embolism; EINSTEIN PE, Oral Direct Factor Xa Inhibitor Rivaroxaban in Patients With Acute Symptomatic Pulmonary Embolism; HOKUSAIVTE, Comparative Investigation of Low Molecular Weight (LMW) Heparin/Edoxaban Tosylate (DUI76b) Versus (LMW) Heparin/Warfarin in the Treatment of Symptomatic Deep-Vein Blood Clots and/or Lung Blood Clots; M-H, Mantel-Haenszel; PE, pulmonary embolism; RE-COVER I, Efficacy and Safety of Dabigatran Compared to Warfarin for 6 Month Treatment of Acute Symptomatic Venous Thromboembolism; RE-COVER II, Phase III Study Testing Efficacy and Safety of Oral Dabigatran Etexilate versus Warfarin for 6 Month Treatment for Acute Symptomatic Venous Thromboembolism (VTE); RE-MEDY, Secondary Prevention of Venous Thrombo Embolism (VTE); RE-SONATE, Twice-daily Oral Direct Thrombin Inhibitor Dabigatran Etexilate in the Long Term Prevention of Recurrent Symptomatic VTE; VTE, venous thromboembolism.

\section{Extended therapy of VTE}

During extended therapy of VTE, the DOAC were as effective as warfarin (RR: 1.44; 95\% CI: 0.79-2.62) and more effective than placebo (RR: 0.20; 95\% CI: 0.09-0.44) in preventing recurrent VTE. However, there was statistical heterogeneity among placebo-controlled studies $(P=0.02)$, mainly due to a greater effect size in reduction of recurrent VTE in RESONATE than in the other studies (Figure 1).

A total of 2,297 patients (DOAC: 1,303; warfarin: 503; placebo: 491) with index PE and 4,414 patients (DOAC: 2,461; warfarin: 953; placebo: 1,000) with index DVT were assessable for recurrent VTE (Figure 2B and C). In the single trial that compared a DOAC with warfarin for extended therapy of VTE (RE-MEDY), the point estimate for recurrent VTE tended to favor warfarin without significant differences between patients with index PE (RR: 2.05; 95\% CI: $0.83-$ 5.03) or index DVT (RR: 1.11; 95\% CI: 0.49-2.50) ( $P$ for subgroup differences $=0.32$ ) (Figure $2 \mathrm{~B}$ ). In trials that compared the DOAC and placebo for extended therapy, the effect on recurrent VTE was also consistent in patients with PE (RR: 0.15; 95\% CI: 0.01-1.82) and in patients with DVT (RR:
0.25; 95\% CI: 0.10-0.61) $(P$ for subgroup differences $=0.71)$ (Figure 2C).

\section{Clinically relevant bleeding}

\section{Initial and long-term treatment of VTE}

The DOAC were associated with a lower risk of CRB than standard treatment in the overall population (RR: 0.72; 95\% CI: $0.57-0.91)$, but there was evidence of statistical heterogeneity across studies $(P<0.00001)$, mainly at the expense of a greater effect size in reduction of $\mathrm{CRB}$ in the studies with dabigatran and apixaban than in studies with rivaroxaban and edoxaban (Figure 3).

The risk of CRB versus standard treatment was consistent in patients with index PE (RR: 0.90; 95\% CI: 0.80-1.02) and index DVT (RR: 0.87; 95\% CI: 0.67-1.12) ( $P$ for subgroup differences $=0.80)$ (Figure 4A).

\section{Extended therapy of VTE}

The DOAC were associated with a lower risk of CRB than warfarin (RR: 0.55 ; 95\% CI: 0.42-0.72) and a higher risk of CRB than placebo (RR: 2.61; 95\% CI: 1.24-5.50). However, 


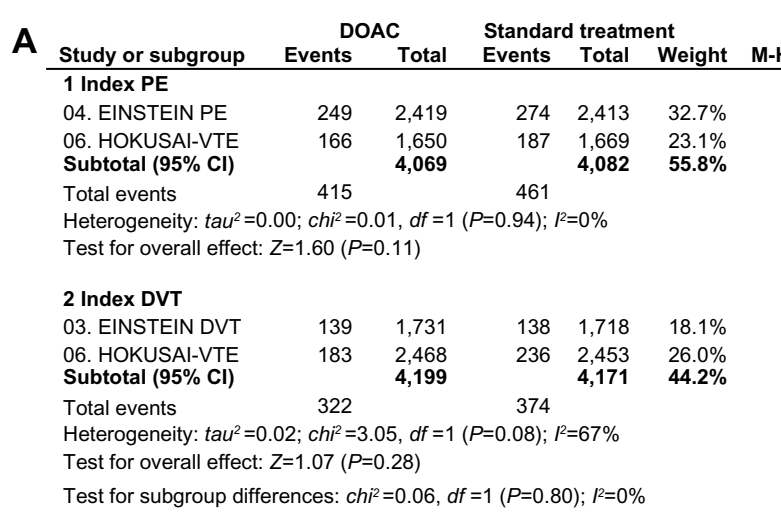
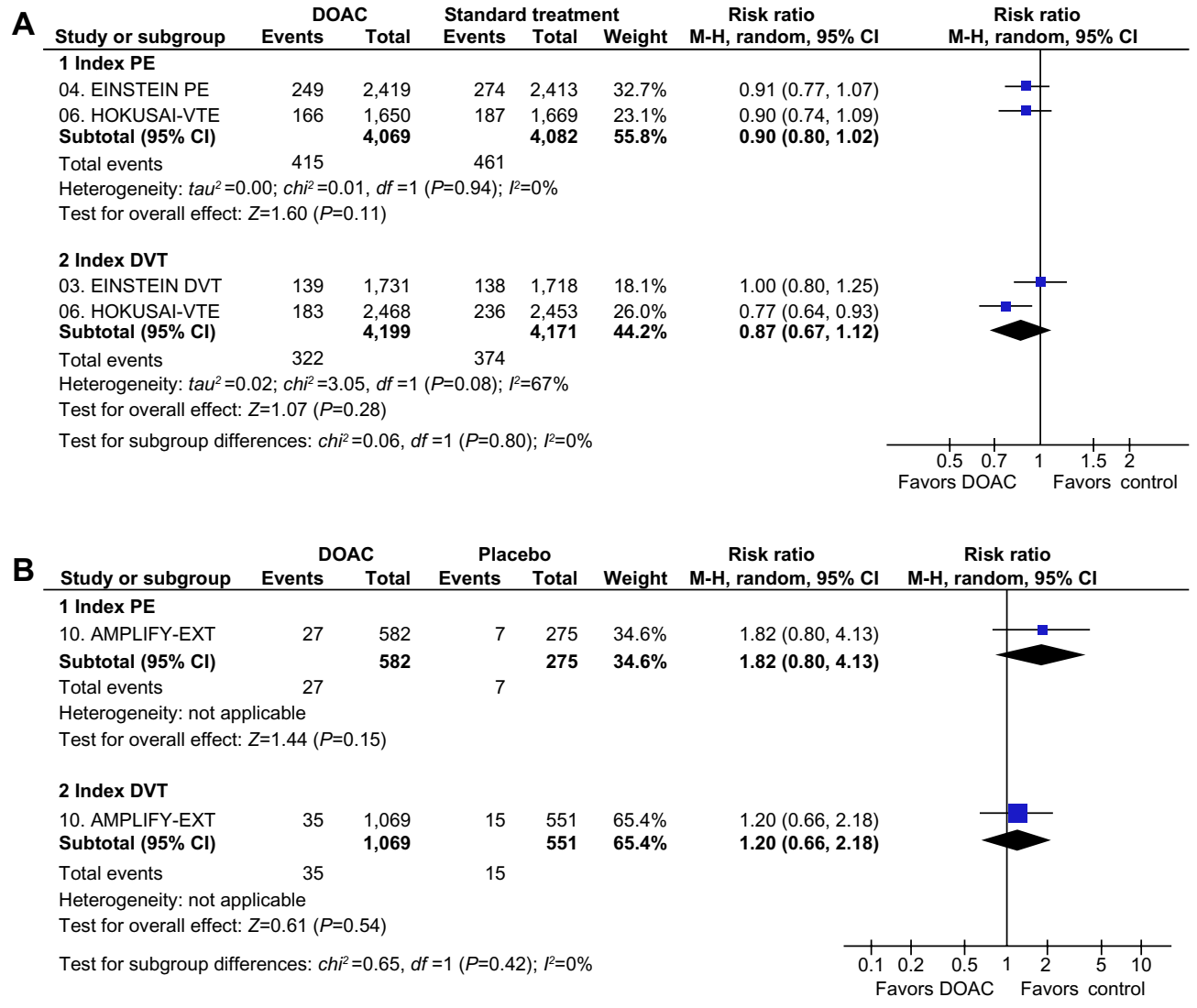

Figure 4 Subgroup analysis of major and clinically relevant nonmajor bleeding events depending on index event (PE or DVT) in clinical trials with DOAC in the treatment of VTE.

Notes: (A) Initial/long-term therapy versus standard treatment. (B) Extended therapy versus placebo.

Abbreviations: AMPLIFY-EXT, Efficacy and Safety Study of Apixaban for Extended Treatment of Deep Vein; Cl, confidence interval; df, degrees of freedom; DOAC, direct oral anticoagulant; DVT, deep vein thrombosis; EINSTEIN DVT, Oral Direct Factor Xa Inhibitor Rivaroxaban in Patients With Acute Symptomatic Deep Vein Thrombosis; EINSTEIN PE, Oral Direct Factor Xa Inhibitor Rivaroxaban in Patients With Acute Symptomatic Pulmonary Embolism; HOKUSAI-VTE, Comparative Investigation of Low Molecular Weight (LMW) Heparin/Edoxaban Tosylate (DUI76b) Versus (LMW) Heparin/Warfarin in the Treatment of Symptomatic Deep-Vein Blood Clots and/or Lung Blood Clots; M-H, Mantel-Haenszel; PE, pulmonary embolism; VTE, venous thromboembolism.

there was evidence of statistical heterogeneity among placebocontrolled studies $(P=0.02)$, mainly at expenses of a higher increase in bleeding in dabigatran and rivaroxaban studies than in the AMPLIFY-EXT study with apixaban (Figure 3).

Disaggregated safety data of extended therapy in patients with PE or DVT were only available from AMPLIFY-EXT. ${ }^{43}$ In that trial, the trend toward increase in risk of CRB with apixaban versus placebo was consistent in patients with index PE (RR: 1.82; 95\% CI: 0.80-4.13) and index DVT (RR: 1.20; 95\% CI: 0.66-2.18) ( $P$ for subgroup differences $=0.42$ ) (Figure 4B). No disaggregated data of CRB depending on index VTE were reported in the remaining three studies in the extended therapy. ${ }^{38,42}$

\section{Clinical outcomes in anticoagulated patients with index PE versus index DVT}

Recurrent VTE and mortality risk were similar in both clinical presentations (index PE and index DVT).
However, patients with index PE had more CRB complications than patients with index DVT during the initial/ long-term anticoagulation therapy (RR: 1.29; 95\% CI: 1.18-1.42) (Table 3). Patients with index PE had similar clinical outcomes than patients with DVT during extended anticoagulation therapy (Table 3 ).

\section{Discussion}

Overall, the DOAC seem associated with similar efficacy and lower bleeding risk than standard therapy following acute VTE. Our analysis shows that the efficacy and safety of the DOAC are consistent regardless of the clinical presentation of acute VTE as hemodynamically stable PE or DVT. The analysis is based on six clinical trials in the initial/long-term therapy of VTE (range: 3-12 months of treatment). ${ }^{36-41}$ These studies included a total of 11,589 randomized patients with index PE and 15,434 randomized patients with index DVT. Across trials, 24\%-46\% of patients with index PE had 
Table 3 Pooled risks of recurrent VTE, CRB, and mortality by index event in patients receiving anticoagulant therapy (DOAC or heparin/warfarin)*

\begin{tabular}{|c|c|c|c|c|}
\hline \multirow[t]{2}{*}{ Clinical setting } & \multicolumn{4}{|l|}{ Outcome } \\
\hline & $\begin{array}{l}\text { Index PE, } \\
\%(n / N)\end{array}$ & $\begin{array}{l}\text { Index DVT, } \\
\%(n / N)\end{array}$ & $\begin{array}{l}\text { \% Absolute risk } \\
\text { difference }(95 \% \mathrm{Cl})\end{array}$ & $\begin{array}{l}\text { Relative risk } \\
\text { difference }(95 \% \mathrm{Cl})\end{array}$ \\
\hline \multicolumn{5}{|l|}{ Initial//ong-term therapy ${ }^{36-41}$} \\
\hline Recurrent VTE & $2.5 \%(290 / 11589)$ & $2.7 \%(4 \mid 2 / I 5434)$ & $-0.2(-0.6$ to 0.2$)$ & $0.94(0.8 \mathrm{I}$ to I.09) \\
\hline CRB & $10.7 \%(876 / 8|5|)$ & $8.3 \%(696 / 8370)$ & $2.4(1.5 \text { to } 3.3)^{\ddagger}$ & $1.29(1.18 \text { to } 1.42)^{\#}$ \\
\hline All-cause mortality ${ }^{\ddagger}$ & $2.2 \%(108 / 4833)$ & $2.5 \%(87 / 3449)$ & $-0.3(-1.04$ to 3.7$)$ & 0.89 (0.67 to I.I7) \\
\hline \multicolumn{5}{|l|}{ Extended therapy $y^{38,42,43}$} \\
\hline Recurrent VTE & $3.0 \%(24 / 8 \mid 2)$ & $3.0 \%(45 / 1522)$ & $0.0(-1.4$ to 1.6$)$ & $1.00(0.62$ to 1.62$)$ \\
\hline Clinically relevant bleeding & $4.6 \%(27 / 582)$ & $3.3 \%(35 / 1069)$ & I.4 $(-0.5$ to 3.6$)$ & $\mathrm{I} .42(0.87$ to $2.3 \mathrm{I})$ \\
\hline
\end{tabular}

Notes: Based on total events and patients with PE or DVT included in clinical trials in the initial/long-term and extended therapy of VTE. \#P<0.05; ${ }^{*}$ Data only available from EINSTEIN PE and EINSTEIN DVT. Data shown in bold font signifies statistical significance, $P<0.05$.

Abbreviations: $\mathrm{Cl}$, confidence interval; CRB, clinically relevant bleeding; DOAC, direct oral anticoagulant; DVT, deep vein thrombosis; EINSTEIN DVT, Oral Direct Factor Xa Inhibitor Rivaroxaban in Patients With Acute Symptomatic Deep Vein Thrombosis; EINSTEIN PE, Oral Direct Factor Xa Inhibitor Rivaroxaban in Patients With Acute Symptomatic Pulmonary Embolism; N, total patients in the trial; n, number of events; PE, pulmonary embolism; VTE, venous thromboembolism.

Table 4 Summary of prescribing information of the DOAC in the treatment of VTE

\begin{tabular}{|c|c|c|c|c|}
\hline Characteristic & $\begin{array}{l}\text { Dabigatran etexilate } \\
\left(\text { Pradaxa }^{\circledR}\right)\end{array}$ & Rivaroxaban (Xarelto ${ }^{\circledR}$ ) & Apixaban (Eliquis ${ }^{\circledR}$ ) & Edoxaban (Lixiana $\left.{ }^{\circledR}\right)^{*}$ \\
\hline \multicolumn{5}{|l|}{ Dosing } \\
\hline Initial therapy & $\begin{array}{l}\text { LMWH or fondaparinux } \\
\text { for at least } 5 \text { days }\end{array}$ & $\begin{array}{l}\text { Rivaroxaban } 15 \mathrm{mg} \text { BID for } \\
21 \text { days ( } 3 \text { weeks) }\end{array}$ & $\begin{array}{l}\text { Apixaban } 10 \mathrm{mg} \text { BID for } \\
7 \text { days (I week) }\end{array}$ & $\begin{array}{l}\text { LMWH or fondaparinux } \\
\text { for at least } 5 \text { days }\end{array}$ \\
\hline $\begin{array}{l}\text { Long-term } \\
\text { therapy }\end{array}$ & Dabigatran I50 mg BID & $\begin{array}{l}\text { Rivaroxaban } 20 \text { mg OD } \\
\text { (I5 mg OD in patients with } \\
\mathrm{CrCl} \mathrm{I5-50} \mathrm{judged} \mathrm{to} \mathrm{be} \mathrm{at} \\
\text { high risk of bleeding) from day } \\
22 \text { onward }\end{array}$ & $\begin{array}{l}\text { Apixaban } 5 \mathrm{mg} \text { BID from } \\
\text { day } 8 \text { onward }\end{array}$ & $\begin{array}{l}\text { Edoxaban } 60 \mathrm{mg} \text { OD } \\
\text { (30 mg in patients with } \\
\text { a CrCl } 30-50 \mathrm{~mL} / \mathrm{min} \text {, } \\
\text { a body weight } \leq 60 \mathrm{~kg} \text { or } \\
\text { concomitant treatment } \\
\text { with potent Pg-p inhibitors) }\end{array}$ \\
\hline $\begin{array}{l}\text { Extended } \\
\text { therapy }\end{array}$ & $\begin{array}{l}\text { Same posology as } \\
\text { long-term therapy }\end{array}$ & $\begin{array}{l}\text { Same posology as long-term } \\
\text { therapy }\end{array}$ & $\begin{array}{l}\text { Dose reduction to } 2.5 \mathrm{mg} \\
\text { BID is recommended following } \\
\text { completion of at least } 6 \text { months } \\
\text { of anticoagulation }\end{array}$ & $\begin{array}{l}\text { Same as long-term therapy } \\
\text { but no clinical experience is } \\
\text { available beyond } 12 \text { months }^{\ddagger}\end{array}$ \\
\hline Intake with food & Not necessary & $\begin{array}{l}\text { Mandatory ( } 39 \% \text { decrease in } \\
\text { absorption when administered } \\
\text { without food) }\end{array}$ & Not necessary & Not necessary \\
\hline $\begin{array}{l}\text { Absorption with } \\
\text { proton pump inhibitors }\end{array}$ & $\begin{array}{l}30 \% \text { decrease (no dose- } \\
\text { adjustment necessary) }\end{array}$ & Not significantly altered & Not significantly altered & Not significantly altered \\
\hline $\begin{array}{l}\text { Relevant } \\
\text { pharmacokinetic } \\
\text { interactions }\end{array}$ & $\begin{array}{l}\text { - Potent Pg-p inhibitors } \\
\text { (contraindicated), } \\
\text { - Potent Pg-p inducers } \\
\text { (not recommended) }\end{array}$ & $\begin{array}{l}\text { - Potent inhibitors of both } \\
\text { P-gP and CYP3A4 } \\
\text { (not recommended), } \\
\text { - Potent inducers of both } \\
\text { P-gP and CYP3A4 } \\
\text { (use with caution) }\end{array}$ & $\begin{array}{l}\text { - Potent inhibitors or inducers } \\
\text { of both P-gp and CYP3A4 } \\
\text { (use with caution) }\end{array}$ & $\begin{array}{l}\text { - Potent Pg-p inhibitors } \\
\text { (dose reduction) (see } \\
\text { long-term therapy) } \\
\text { - Potent Pg-p inducers (no } \\
\text { specific recommendations } \\
\text { available) }\end{array}$ \\
\hline $\begin{array}{l}\text { Relevant } \\
\text { pharmacodynamic } \\
\text { interactions }\end{array}$ & $\begin{array}{l}\text { Drugs that alter } \\
\text { hemostasis }\end{array}$ & Drugs that alter hemostasis ${ }^{\pi}$ & Drugs that alter hemostasis ${ }^{\pi}$ & $\begin{array}{l}\text { Drugs that alter } \\
\text { hemostasis }\end{array}$ \\
\hline $\begin{array}{l}\text { Use in renal } \\
\text { insufficiency }\end{array}$ & $\begin{array}{l}\text { Contraindicated in } \\
\text { severe renal insufficiency } \\
(\mathrm{CrCl}<30 \mathrm{~mL} / \mathrm{min})\end{array}$ & $\begin{array}{l}\text { Not recommended if } \\
\mathrm{CrCl}<15 \mathrm{~mL} / \mathrm{min} \text { Dose- } \\
\text { adjustment in some cases (see } \\
\text { long-term therapy above) }\end{array}$ & $\begin{array}{l}\text { Not recommended if } \\
\mathrm{CrCl}<15 \mathrm{~mL} / \mathrm{min}\end{array}$ & $\begin{array}{l}\text { Dose adjustment in some } \\
\text { cases (see long-term therapy } \\
\text { above). No data available in } \\
\text { severe renal insufficiency) }\end{array}$ \\
\hline
\end{tabular}

Notes: "Not approved yet (as of August 2014) in the European Union and other regions for the treatment of VTE. "In selected patients at high risk of recurrence, according

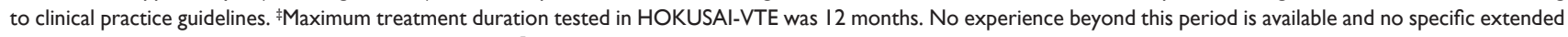
treatment studies with edoxaban have been conducted). IIncludes other anticoagulants (use contraindicated unless switching therapy), fibrinolytics, and antiplatelet drugs (use with caution unless formal contraindication). Grade I-2, strong-weak evidence; Grade A-B-C, high-moderate-low quality of data.

Abbreviations: BID, twice-daily; BP, blood pressure; $\mathrm{CrCl}$, creatine chloride; DOAC, direct oral anticoagulant; HOKUSAI-VTE, Comparative Investigation of Low Molecular Weight (LMW) Heparin/Edoxaban Tosylate (DUI76b) Versus (LMW) Heparin/Warfarin in the Treatment of Symptomatic Deep-Vein Blood Clots and/or Lung Blood Clots; LMWH, low-molecular-weight heparin; min, minute; OD, once-daily; Pg-p, P-glycoprotein; VTE, venous thromboembolism. 
anatomically extensive PE, ${ }^{39-41}$ and $28 \%$ of patients with index PE had RVD. ${ }^{41}$ Available data in these subgroups, although scarce, suggest that the effect in patients with index $\mathrm{PE}$ is consistent regardless of anatomical extension of $\mathrm{PE},{ }^{34}$ or presence/absence of RVD. ${ }^{41}$

In the extended therapy, we found a reduction in recurrent VTE with the DOAC in comparison with placebo, which was also consistent in patients with PE and in patients with DVT. On the contrary, the point estimate for the RR of recurrent VTE disfavored dabigatran versus warfarin in the RE-MEDY trial, particularly in patients with PE. Moreover, the trend toward a poorer efficacy of dabigatran versus warfarin during extended therapy of VTE was further suggested by the numerical increase in acute coronary syndromes (ACS) (13 versus three patients). The TTR in RE-MEDY was 65\%, better than in all the remaining studies with the DOAC in the treatment of VTE. These data may suggest that patients with index PE who remain well controlled while on extended therapy with warfarin should not generally be switched to dabigatran, as it could potentially result in an increased risk of thromboembolism. Since the RE-MEDY trial is so far the only study comparing the DOAC and warfarin in extended anticoagulant therapy in patients with VTE, these results must be interpreted with caution and are not necessarily applicable with other DOAC. Moreover, in the RE-SONATE study (extended therapy with dabigatran or placebo), the rates of recurrent VTE and ACS with dabigatran $(0.4 \%$ and $0.1 \%$, respectively) were much lower than those in the dabigatran arm of the RE-MEDY study (1.8\% and $0.9 \%$, respectively). These differences could be explained by an optimal quality of anticoagulation with warfarin in REMEDY and by different baseline risk of treatment groups and follow-up duration between trials. Whether dabigatran increases the risk of ACS or the findings are due to a more protective effect of warfarin than of dabigatran against ACS is still unclear.

In extended therapy, dabigatran showed a significantly lower risk of bleeding than warfarin in RE-MEDY, ${ }^{42}$ which is consistent with the lower bleeding tendency of all DOAC versus standard initial/long-term therapy. On the contrary, we found an increase in CRB with the DOAC versus placebo, which was heterogeneous across trials. The heterogeneity found may be due to differences in bleeding definitions across trials or might reflect differences in the bleeding profile of each of the DOAC, as they are different compounds with unique pharmacological characteristics. Head-to-head comparisons between the DOAC are needed to solve this issue.
Important differences are apparent between trials regarding the dosing regime (single-drug approach used in rivaroxaban and apixaban trials versus heparin lead-in used in dabigatran and edoxaban trials) that have implications when prescribing the DOAC in patients with VTE (Table 4). In addition, there are other issues to bear in mind when prescribing the new compounds, like their potential for drugdrug of food-drug interactions and appropriate use in renal insufficiency (Table 4).

A single-drug regimen with rivaroxaban or apixaban may simplify treatment of acute PE, thus allowing for outpatient treatment in low-risk $\mathrm{PE}^{6}$ or early discharge in intermediaterisk PE patients and potentially reducing hospital stays. A post hoc analysis of EINSTEIN studies has shown that the proportion of hospitalized patients for $\mathrm{PE}$ with a length of stay of 5 days or fewer receiving rivaroxaban was $45 \%$ compared with 33\% for enoxaparin/VKA. ${ }^{45}$ Reduction in subsequent hospitalizations after initial discharge has been reported with apixaban in the acute/long-term therapy versus standard treatment (AMPLIFY) ${ }^{46}$ and during extended therapy versus placebo (AMPLIFY-EXT). ${ }^{47}$ Limitations of these analyses include their post hoc nature and well-monitored clinical trial setting, in which decisions on admission and discharge could vary from real-world management.

The DOAC may provide an alternative to warfarin for extended therapy of PE, particularly in those patients considered to be at high risk of bleeding. Patients with VTE and cancer are among those patients who have a high risk of both recurrence and bleeding. DOAC have shown promising results in patients with cancer in comparison with warfarin. ${ }^{48,49}$ However, LMWH instead of VKA is the standard of care in VTE associated with cancer. ${ }^{50}$ Further head-to-head comparative trials between the DOAC and LMWH are needed to recommend the use of the DOAC in VTE associated with cancer.

Heparin-induced thrombocytopenia (HIT) is a rare but serious complication of heparin treatment.$^{51} \mathrm{DOAC}$ may provide an alternative for anticoagulation in patients with VTE and with history of HIT, because they do not interact with PF4 in vitro. ${ }^{52-54}$ A clinical study is underway to investigate rivaroxaban for treatment of patients with current suspected or confirmed HIT $(n=200)$ (Clinicaltrials.gov identifier: NCT01598168). ${ }^{55}$

The lack of validated and currently available antidotes is one of the drawbacks of the DOAC. ${ }^{48}$ Adequate supportive care and temporary removal of all antithrombotic drugs constitute the basis for management of serious bleeding complications. ${ }^{56}$ Prohemostatic agents (unactivated or 
activated prothrombin complex concentrate and activated factor VIIa) have been tried for the DOAC with varying success. ${ }^{56}$ Hemodialysis can remove $50 \%-60 \%$ of circulating dabigatran, ${ }^{10}$ while administration of activated charcoal may be useful to reduce absorption of rivaroxaban or apixaban if taken $<6$ hours after overdose or accidental ingestion. ${ }^{11,12}$ Highly specific reversal agents for the direct thrombin and FXa inhibitors are under development and might be available during the next years. ${ }^{56}$

Other drawbacks of the DOAC include their higher costs in comparison with VKA and the uncertainty about the adherence to therapy in day-to-day practice. Since the DOAC have a shorter half-life ( $<24$ hours) than warfarin (36-42 hours), suboptimal adherence may be more dangerous for the DOAC than for warfarin. Furthermore, some DOAC have twice-daily dosing schedules (Table 4), which may be more difficult for some patients with DVT or PE to adhere to than a daily regimen, particularly in the long term. ${ }^{57}$ However, no head-to-head comparisons for checking compliance with once-daily versus twice-daily regimes of DOAC are available, and therefore no firm conclusions can be drawn in this respect.

\section{Conclusion}

The DOAC are as effective as, and probably safer than standard treatment of hemodynamically stable PE. The efficacy and safety of the DOAC seem consistent regardless anatomical extension of PE (extensive, intermediate, or limit) or presence/absence of RVD, although the data are limited. For extended therapy, the DOAC are more effective than placebo in preventing recurrent VTE but are associated with an increase in CRB either in patients with PE or DVT.

\section{Disclosure}

The contents of this review are solely the responsibility of the authors and do not necessarily represent the official view of their institutions or any other party. No funding/support grant was received for this review. A Gómez-Outes, ML SuárezGea, AI Terleira-Fernández, and E Vargas-Castrillón declare no conflicts of interest. R Lecumberri declares personal fees from Bayer, Boehringer Ingelheim, Bristol-Myers Squibb, and Daiichi Sankyo, and grants and personal fees from Rovi Pharmaceuticals, outside the submitted work.

\section{References}

1. Silverstein MD, Heit JA, Mohr DN, Petterson TM, O'Fallon WM, Melton LJ 3rd. Trends in the incidence of deep vein thrombosis and pulmonary embolism: a 25-year population-based study. Arch Intern Med. 1998;158(6):585-593.
2. Kearon C. Natural history of venous thromboembolism. Circulation. 2003;107(23 Suppl 1):I22-I30.

3. Stein PD, Matta F, Musani MH, Diaczok B. Silent pulmonary embolism in patients with deep venous thrombosis: a systematic review. $\mathrm{Am} \mathrm{J}$ Med. 2010;123(5):426-431.

4. Buller HR, Lensing AW, Prins MH, et al. A dose-ranging study evaluating once-daily oral administration of the factor Xa inhibitor rivaroxaban in the treatment of patients with acute symptomatic deep vein thrombosis: the Einstein-DVT Dose-Ranging Study. Blood. 2008;112(6): 2242-2247.

5. Torbicki A, Perrier A, Konstantinides S, et al. Guidelines on the diagnosis and management of acute pulmonary embolism: the Task Force for the Diagnosis and Management of Acute Pulmonary Embolism of the European Society of Cardiology (ESC). Eur Heart J. 2008;29(18):2276-2315.

6. Aujesky D, Perrier A, Roy PM, et al. Validation of a clinical prognostic model to identify low-risk patients with pulmonary embolism. J Intern Med. 2007;261(6):597-604.

7. Kearon C, Akl EA, Comerota AJ, et al. Antithrombotic therapy for VTE disease: antithrombotic therapy and prevention of thrombosis, 9th ed: American College of Chest Physicians Evidence-Based Clinical Practice Guidelines. Chest. 2012;141(Suppl 2):e419S-e494S.

8. Gómez-Outes A, Suárez-Gea ML, Calvo-Rojas G, et al. Discovery of anticoagulant drugs: a historical perspective. Curr Drug Discov Technol. 2012;9(2):83-104.

9. Cabral KP. Pharmacology of the new target-specific oral anticoagulants. J Thromb Thrombolysis. 2013;36(2):133-140.

10. European Medicines Agency. Pradaxa ${ }^{\circledR}$ - Summary of Product Characteristics; 2014. Available from: http://www.ema.europa. eu/docs/en_GB/document_library/EPAR_-_Product_Information/ human/000829/WC500041059.pdf.

11. European Medicines Agency. Xarelto ${ }^{\circledR}$ - Summary of Product Characteristics; 2014. Available from: http://www.ema.europa. eu/docs/en_GB/document_library/EPAR_-_Product_Information/ human/000944/WC500057108.pdf.

12. European Medicines Agency. Eliquis ${ }^{\circledR}$ - Summary of Product Characteristics; 2014. Available from: http://www.ema.europa. eu/docs/en_GB/document_library/EPAR_-_Product_Information/ human/002148/WC500107728.pdf.

13. Lip GY, Agnelli G. Edoxaban: a focused review of its clinical pharmacology. Eur Heart J. 2014;35(28):1844-1855.

14. Mungall D. BIBR-1048 Boehringer Ingelheim. Curr Opin Investig Drugs. 2002;3(6):905-907.

15. Stangier J. Clinical pharmacokinetics and pharmacodynamics of the oral direct thrombin inhibitor dabigatran etexilate. Clin Pharmacokinet. 2008;47(5):285-295.

16. Trocóniz IF, Tillmann C, Liesenfeld KH, Schäfer HG, Stangier J. Population pharmacokinetic analysis of the new oral thrombin inhibitor dabigatran etexilate (BIBR 1048) in patients undergoing primary elective total hip replacement surgery. J Clin Pharmacol. 2007;47(3): 371-382.

17. Blech S, Ebner T, Ludwig-Schwellinger E, Stangier J, Roth W. The metabolism and disposition of the oral direct thrombin inhibitor, dabigatran, in humans. Drug Metab Dispos. 2008;36(2):386-399.

18. Kubitza D, Becka M, Voith B, Zuehlsdorf M, Wensing G. Safety, pharmacodynamics, and pharmacokinetics of single doses of BAY 59-7939, an oral, direct factor Xa inhibitor. Clin Pharmacol Ther. 2005;78(4): $412-421$.

19. Kubitza D, Becka M, Wensing G, Voith B, Zuehlsdorf M. Safety, pharmacodynamics, and pharmacokinetics of BAY 59-7939 - an oral, direct Factor Xa inhibitor - after multiple dosing in healthy male subjects. Eur J Clin Pharmacol. 2005;61(12):873-880.

20. Kubitza D, Becka M, Roth A, Mueck W. Dose-escalation study of the pharmacokinetics and pharmacodynamics of rivaroxaban in healthy elderly subjects. Curr Med Res Opin. 2008;24(10):2757-2765.

21. Lang D, Freudenberger C, Weinz C. In vitro metabolism of rivaroxaban, an oral, direct factor Xa inhibitor, in liver microsomes and hepatocytes of rats, dogs, and humans. Drug Metab Dispos. 2009;37(5):1046-1055. 
22. Wong PC, Crain EJ, Xin B, et al. Apixaban, an oral, direct and highly selective factor Xa inhibitor: in vitro, antithrombotic and antihemostatic studies. J Thromb Haemost. 2008;6(5):820-829.

23. Wang L, Zhang D, Raghavan N, et al. In vitro assessment of metabolic drug-drug interaction potential of apixaban through cytochrome P450 phenotyping, inhibition, and induction studies. Drug Metab Dispos. 2010;38(3):448-458.

24. Raghavan N, Frost CE, Yu Z, et al. Apixaban metabolism and pharmacokinetics after oral administration to humans. Drug Metab Dispos. 2009;37(1):74-81.

25. Furugohri T, Isobe K, Honda Y, et al. DU-176b, a potent and orally active factor Xa inhibitor: in vitro and in vivo pharmacological profiles. J Thromb Haemost. 2008;6(9):1542-1549.

26. Morishima Y, Honda Y, Kamisato C, et al. Comparison of antithrombotic and haemorrhagic effects of edoxaban, an oral direct factor Xa inhibitor, with warfarin and enoxaparin in rats. Thromb Res. 2012;130(3): 514-519.

27. Ogata K, Mendell-Harary J, Tachibana M, et al. Clinical safety, tolerability, pharmacokinetics, and pharmacodynamics of the novel factor Xa inhibitor edoxaban in healthy volunteers. J Clin Pharmacol. 2010;50(7): 743-753.

28. Bathala MS, Masumoto H, Oguma T, He L, Lowrie C, Mendell J. Pharmacokinetics, biotransformation, and mass balance of edoxaban, a selective, direct factor Xa inhibitor, in humans. Drug Metab Dispos. 2012;40(12):2250-2255

29. Masumoto H, Yoshigae Y, Watanabe K, Takakusa H, Okazaki O, Izumi T. In vitro metabolism of edoxaban and the enzymes involved in the oxidative metabolism of edoxaban. AAPS J. 2010;12(S2):W4308 [abstract].

30. Kawaji H, Ishii M, Tamaki Y, Sasaki K, Takagi M. Edoxaban for prevention of venous thromboembolism after major orthopedic surgery. Orthop Res Rev. 2012;4:53-64.

31. Higgins JP, Altman DG, Gøtzsche PC, et al. The Cochrane Collaboration's tool for assessing risk of bias in randomised trials. BMJ. 2011;343:d5928.

32. Liberati A, Altman DG, Tetzlaff J, et al. The PRISMA statement for reporting systematic reviews and meta-analyses of studies that evaluate healthcare interventions: explanation and elaboration. BMJ. 2009;339:b2700.

33. DerSimonian R, Laird N. Meta-analysis in clinical trials. Control Clin Trials. 1986;7(3):177-188.

34. Cochran WG. The combination of estimates from different experiments. Biometrics. 1954;10(1):101-129.

35. Higgins JPT, Thompson SG, Deeks JJ, Altman DG. Measuring inconsistency in meta-analyses. BMJ. 2003;327(7414):557-560.

36. Schulman S, Kearon C, Kakkar AK, et al. Dabigatran versus warfarin in the treatment of acute venous thromboembolism. $N$ Engl J Med. 2009;361(24):2342-2352.

37. Schulman S, Kakkar AK, Goldhaber SZ, et al. Treatment of acute venous thromboembolism with dabigatran or warfarin and pooled analysis. Circulation. 2014;129(7):764-772.

38. EINSTEIN Investigators, Bauersachs R, Berkowitz SD, et al. Oral rivaroxaban for symptomatic venous thromboembolism. N Engl J Med. 2010;363(26):2499-2510.

39. EINSTEIN-PE Investigators, Büller HR, Prins $\mathrm{MH}$, et al. Oral rivaroxaban for the treatment of symptomatic pulmonary embolism. $N$ Engl J Med. 2012;366(14):1287-1297.

40. Agnelli G, Buller HR, Cohen A, et al. Oral apixaban for the treatment of acute venous thromboembolism. N Engl J Med. 2013;369(9):799-808.

41. The Hokusai-VTE Investigators. Edoxaban versus warfarin for the treatment of symptomatic venous thromboembolism. $N$ Engl J Med. 2013;369(15):1406-1415.

Vascular Health and Risk Management

\section{Publish your work in this journal}

Vascular Health and Risk Management is an international, peerreviewed journal of therapeutics and risk management, focusing on concise rapid reporting of clinical studies on the processes involved in the maintenance of vascular health; the monitoring, prevention and treatment of vascular disease and its sequelae; and the involvement of
42. Schulman S, Kearon C, Kakkar AK, et al. Extended use of dabigatran, warfarin, or placebo in venous thromboembolism. $N$ Engl J Med. 2013;368(8):709-718.

43. Agnelli G, Buller HR, Cohen A, et al. Apixaban for extended treatment of venous thromboembolism. N Engl J Med. 2013;368(8):699-708.

44. van Gogh Investigators, Buller HR, Cohen AT, et al. Idraparinux versus standard therapy for venous thromboembolic disease. $N$ Engl J Med. 2007;357:1094-1104.

45. van Bellen B, Bamber L, Correa de Carvalho F, Prins M, Wang M, Lensing AW. Reduction in the length of stay with rivaroxaban as a single-drug regimen for the treatment of deep vein thrombosis and pulmonary embolism. Curr Med Res Opin. 2014;30(5):829-837.

46. Liu X, Johnson M, Mardekian J, Phatak H, Thompson J, Cohen A. Apixaban reduces hospitalizations in patients with VTE: an analysis of the AMPLIFY trial. J Am Coll Cardiol. 2014;63(Suppl 12):A2045 [abstract].

47. Liu X, Thompson J, Phatak H, Mardekian J, Porcari AR, Johnson MR. Apixaban reduces hospitalization in patients with venous thromboembolism: An analysis of the AMPLIFY-EXT Trial. Blood. 2013;122:3638 [abstract].

48. Gómez-Outes A, Suárez-Gea ML, Lecumberri R, Terleira-Fernández AI, Vargas-Castrillón E, Rocha E. Potential role of new anticoagulants for prevention and treatment of venous thromboembolism in cancer patients. Vasc Health Risk Manag. 2013;9:207-228.

49. van der Hulle T, den Exter PL, Kooiman J, van der Hoeven JJ, Huisman MV, Klok FA. Meta-analysis of the efficacy and safety of new oral anticoagulants in patients with cancer-associated acute venous thromboembolism. J Thromb Haemost. 2014;2(7):1116-1120.

50. Farge D, Debourdeau P, Beckers M, et al. International clinical practice guidelines for the treatment and prophylaxis of venous thromboembolism in patients with cancer. J Thromb Haemost. 2013;11(1): 56-70.

51. Linkins LA, Dans AL, Moores LK, et al. Treatment and prevention of heparin-induced thrombocytopenia: antithrombotic therapy and prevention of thrombosis, 9th ed: American College of Chest Physicians Evidence-Based Clinical Practice Guidelines. Chest. 2012; 141(Suppl 2):e495S-e530S.

52. Krauel K, Hackbarth C, Fürll B, Greinacher A. Heparin-induced thrombocytopenia: in vitro studies on the interaction of dabigatran, rivaroxaban, and low-sulfated heparin, with platelet factor 4 and antiPF4/heparin antibodies. Blood. 2012;119(5):1248-1255.

53. Walenga JM, Prechel M, Jeske WP, et al. Rivaroxaban - an oral, direct factor Xa inhibitor - has potential for the management of patients with heparin-induced thrombocytopenia. Br J Haematol. 2008;143(1): 92-99

54. Walenga JM, Prechel M, Hoppensteadt D, et al. Apixaban as an alternate oral anticoagulant for the management of patients with heparin-induced thrombocytopenia. Clin Appl Thromb Hemost. 2013;19(5):482-487.

55. Linkins LA, Warkentin TE, Pai M, et al. Design of the rivaroxaban for heparin-induced thrombocytopenia study. J Thromb Thrombolysis. Epub February 19, 2014.

56. Suryanarayan D, Schulman S. Potential antidotes for reversal of old and new oral anticoagulants. Thromb Res. 2014;133(Suppl 2): S158-S166.

57. Laliberté F, Bookhart BK, Nelson WW, et al. Impact of once-daily versus twice-daily dosing frequency on adherence to chronic medications among patients with venous thromboembolism. Patient. 2013;6(3) 213-224.

\section{Dovepress}

metabolic disorders, particularly diabetes. This journal is indexed on PubMed Central and MedLine. The manuscript management system is completely online and includes a very quick and fair peer-review system, which is all easy to use. Visit http://www.dovepress.com/ testimonials.php to read real quotes from published authors. 